\title{
Infrared spectroscopy of ion-induced cross-linked sulfonated poly(ether ether ketone)
}

Kierstyn Anderson ${ }^{1}$, Erin Kingston ${ }^{1}$, Joseph Romeo ${ }^{1}$, Jonathan Doan ${ }^{1}$, Neili Loupe ${ }^{1}$, Nicholas Dimakis ${ }^{2}$, Eugene S. Smotkin ${ }^{1}$ *

${ }^{1}$ Department of Chemistry and Chemical Biology, Northeastern University, Boston MA 02115, USA

${ }^{2}$ Department of Physics, University of Texas Rio Grande Valley, Edinburg, TX 78539

KEYWORDS Cross-linking, SPEEK, Infrared spectroscopy

\section{Abstract}

The dehydration of SPEEK-[H] (protonated sulfonated poly(ether ether ketone)) converts 3-fold symmetric $\left(\mathrm{C}_{3 \mathrm{~V}}\right)$ hydrated sulfonate sites to sulfonic acid sites with no local symmetry $\left(\mathrm{C}_{1}\right)$. Like Nafion-[H], SPEEK-[H] $\mathrm{C}_{3 \mathrm{~V}}$ and $\mathrm{C}_{1}$ environments afford IR group modes $\left(\mathrm{C}_{3 \mathrm{~V}, \mathrm{HF}}\right.$ $\left(1087 \mathrm{~cm}^{-1}\right) ; C_{3 V, L F}\left(1026 \mathrm{~cm}^{-1}\right)$ and $\left.C_{1, \mathrm{HF}}\left(1362 \mathrm{~cm}^{-1}\right) ; C_{1, \mathrm{LF}}\left(904 \mathrm{~cm}^{-1}\right)\right)$ due to the mechanical coupling of vibrational internal coordinates of an ether link with those of the sulfonate or sulfonic acid exchange site. $\mathrm{C}_{3 \mathrm{~V}}$ and $\mathrm{C}_{1}$ bands are inversely correlated during membrane hydration/dehydration. Hydrated SPEEK-[M] $\left(\mathrm{M}: \mathrm{Cu}^{2+}, \mathrm{Ni}^{2+}, \mathrm{Cd}^{2+}, \mathrm{Pb}^{2+}, \mathrm{Sr}^{2+}\right.$ or $\left.\mathrm{Ba}^{2+}\right)$ exhibits SPEEK- $[\mathrm{H}] \mathrm{C}_{3 \mathrm{~V}}$ bands because cation waters of hydration preclude binding to the hydrated exchange site. When cation hydration spheres are thermally stripped at high vacuum, SPEEK[M] $\mathrm{C}_{3 \mathrm{~V}}$ bands supplant SPEEK-[H] $\mathrm{C}_{3 \mathrm{~V}}$ bands, inducing SPEEK cross-linking. Incomplete cross-linking is evidenced by low intensities of SPEEK-[M] $\mathrm{C}_{1, \mathrm{HF}}$ bands. The $1362 \mathrm{~cm}^{-1}$ band intensities are inversely correlated with cation hydration enthalpies. 


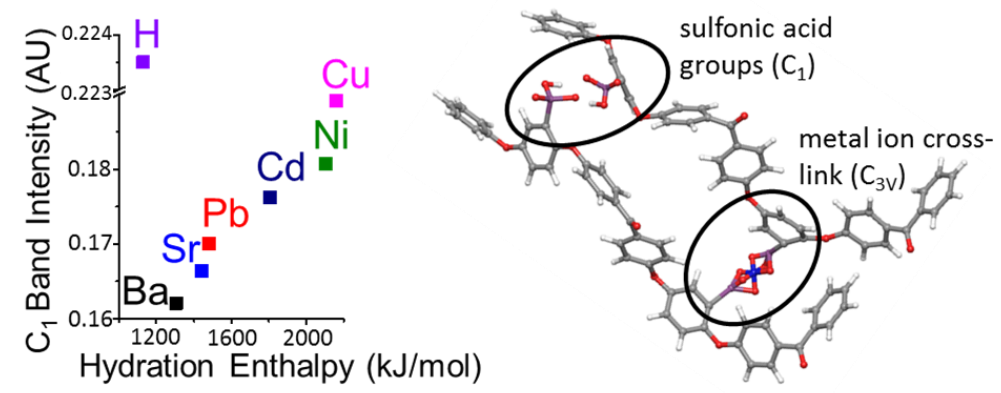

\section{Graphical Abstract}

\section{Introduction}

Nafion and sulfonated poly(ether ether ketone) (SPEEK) membranes (Fig. 1) are ideal for

4 polymer electrolyte membrane (PEM) fuel cells because of the high proton conductivity afforded

5 by sulfonate exchange groups $\left(-\mathrm{SO}_{3}{ }^{-}\right)$and their robust backbone structures. ${ }^{1,2,3}$ Nafion, a

6 perfluorinated carbon backbone with vibrationally hinged (ether link) side chains that terminate

7 with a sulfonate exchange site, has been the dominant PEM fuel cell electrolyte for several

8 decades. $^{4-6}$ Although Nafion has excellent chemical stability and proton conductivity, ${ }^{4}$ it is

9 expensive, has diminished conductivity above $90^{\circ} \mathrm{C},{ }^{4,7,8}$ is subject to a free radical catalyzed

10 unzipping mechanism ${ }^{3}$ and generates fluorinated toxins when incinerated. ${ }^{9,}{ }^{10}$ SPEEK is lower

11 cost, has high chemical, thermal, and mechanical stability, ${ }^{1,7,11}$ and is environmentally

12 friendly. ${ }^{12,2,3,13,14}$

Differences in morphology and microstructure account for functional discrepancies (e.g.,

14 proton conductivity, thermal stability) between SPEEK and Nafion. ${ }^{15}$ SPEEK has narrower

15 aqueous channels and dead ended aqueous confines that result in lower proton conductivity than

16 Nafion with the same degree of sulfonation. ${ }^{3,15}$ While proton conductivity increases with degree

17 of sulfonation, ${ }^{14,16,17}$ membrane swelling also increases, diminishing mechanical strength. 
1 degrees of sulfonation ${ }^{8,13,11,18,20}$ to the extent that highly sulfonated cross-linked SPEEK can

2 outperform Nafion. ${ }^{21,22}$ Unfortunately the benefits of cross-linking ${ }^{8,13,19,20,21,22,23}$ come at the 3 expense of lower proton conductivity. ${ }^{19}$

$4 \quad$ SPEEK cross-linking methods are not well developed due to the rigid backbone structure.

5 SPEEK ether links are hampered vibrational hinges because their lone pair electrons are

6 delocalized by resonance. While most cross-linking strategies involve covalent bonding, ionic

7 bonding ${ }^{8}$ and a combination of both ${ }^{20}$ have been explored. Chemical (covalent) cross-linking ${ }^{22,24}$

8 is done through electron beam irradiation, ${ }^{11} \mathrm{UV}$ irradiation, ${ }^{23}$ free radical reactions or the use of

9 PEEK precursors that generate cross-linked products. ${ }^{8}$ Physical methods are less understood, ${ }^{22}$

10 but provide facile methods for study of cross-linking. Ionic cross-linking is a physical method

11 that requires the maintenance of electrical neutrality. ${ }^{22}$ Narducci et al. suggest ionic cross-linking

12 by divalent ions in hydrated SPEEK membranes. ${ }^{25}$ Cross-linking with $\mathrm{Sr}^{2+}$ and $\mathrm{Ba}^{2+}$ has been

13 reported. ${ }^{8,} 22$ Quezado et al. conducted a comprehensive FTIR study of metal ion-water

14 interactions in Nafion at low levels of hydration. ${ }^{26}$ Their study of 20 cations at wavenumbers

15 above $1550 \mathrm{~cm}^{-1}$ showed that Lewis acid and base strengths of cations and anions are good

16 indicators of their affinity for each other and of the resistance of cation-anion pairs to disruption

17 by water molecules. Our recent report on interactions between cations and the exchange group,

18 in totally dehydrated Nafion, focused on wavenumbers below $1200 \mathrm{~cm}^{-1}$ : Strong binding

19 between cations and the dehydrated exchange group feature $\mathrm{C}_{3 \mathrm{~V}}$ local symmetry with substantial

20 orbital overlap between the metal ion and the exchange site sulfur atom. ${ }^{27}$ Our crystal orbital

21 overlap population calculations also showed a surprisingly high level of orbital overlap between

22 lithium and the exchange site sulfur. ${ }^{27}$ This explains why lithium-exchanged sulfonated ionomers 
1 are not good battery electrolytes. ${ }^{28,} 29$ Quezado et al. also reported anomalously strong

2 interactions between $\mathrm{Li}^{+}$and Nafion exchange sites. ${ }^{26}$

The proximity of the exchange site to an ether link (Fig. 1, red circles) yields striking

4 similarities between Nafion and SPEEK vibrational spectroscopy. They both have IR group

5 modes derived from the mechanical coupling of the exchange site with a nearest neighbor ether

6 link (e.g., COC-A in the case of Nafion). ${ }^{30}$ These IR group modes are categorized in terms of the

7 local symmetry of the exchange site, which depends on the state-of-hydration and the charge

8 compensating ion. ${ }^{3,27,30-33}$ When the membrane is hydrated, the exchange site is dissociated to

9 the sulfonate form and has a $\mathrm{C}_{3 \mathrm{~V}}$ local symmetry. At lower states-of-hydration the exchange site

10 associates to a sulfonic acid form that has no local symmetry (i.e. $\mathrm{C}_{1}$ ). Thus group modes that are

11 consequences of the mechanical coupling of the exchange site to the nearest neighbor ether link

12 are categorized as either $\mathrm{C}_{3 \mathrm{~V}}$ or $\mathrm{C}_{1}$ group modes.

(a)

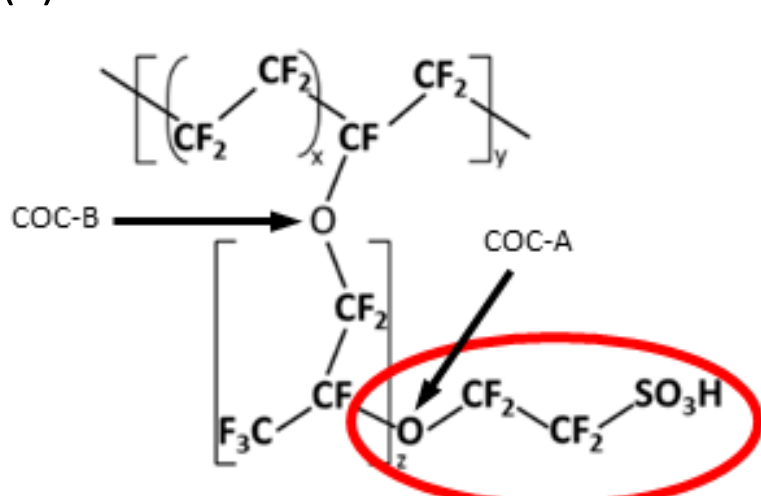

(b)

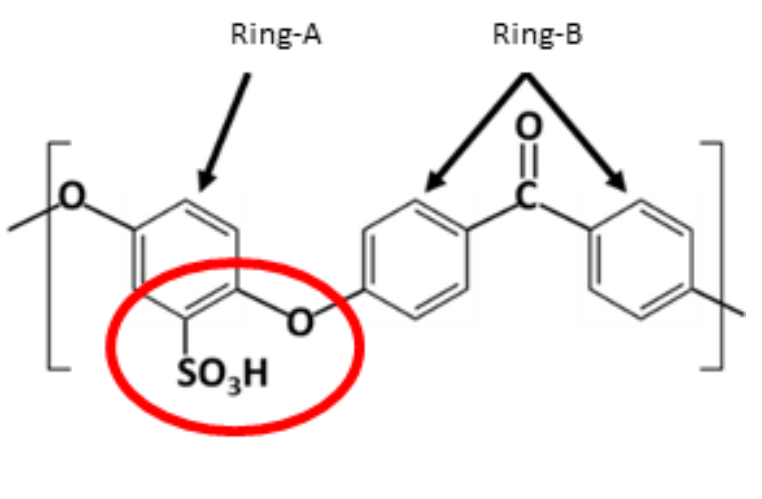

Figure 1: Chemical repeat units of (a) Nafion and (b) SPEEK. The proximity of the ion exchange

14 site to an ether $\operatorname{link}^{34}$ (circled in red) is common to both structures. 
1 In Nafion-[H], the higher frequency $\mathrm{C}_{3 \mathrm{~V}}$ mode $\left(1060 \mathrm{~cm}^{-1}\right)$, referred to as $\mathrm{C}_{3 \mathrm{~V}, \mathrm{HF}}$, is dominated by

2 COC-A motions that are mechanically coupled to the exchange site. The $\mathrm{C}_{3 \mathrm{~V}, \mathrm{LF}}\left(969 \mathrm{~cm}^{-1}\right)$ is

3 dominated by exchange site motions coupled to a smaller COC-A contribution. ${ }^{30-32}$ Proton

4 association during dehydration of Nafion- $[\mathrm{H}]$ yields the sulfonic acid form of the exchange site (-

$\left.5 \mathrm{SO}_{3} \mathrm{H}\right)$ which has no local symmetry $\left(\mathrm{C}_{1}\right) .{ }^{3}$ This gives rise to Nafion $\mathrm{C}_{1, \mathrm{HF}}\left(1414 \mathrm{~cm}^{-1}\right)$ and $\mathrm{C}_{1, \mathrm{LF}}$

$6 \quad\left(910 \mathrm{~cm}^{-1}\right)$ group modes, derived from the mechanically coupled internal coordinates of COC-A

7 and the $-\mathrm{SO}_{3} \mathrm{H}$ exchange site. ${ }^{27}$

8 The assignment of IR bands attributed to the side chain of hydrated Nafion in terms of a 9 single functional group has led to enormous confusion. ${ }^{30,35-37}$ For example, the $1060 \mathrm{~cm}^{-1}$ is

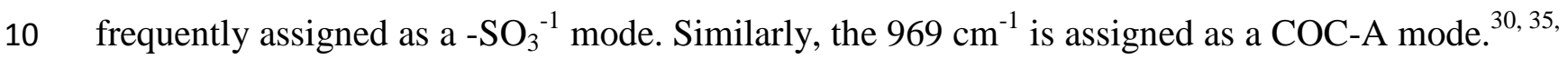
1136 These single functional group assignments preclude understanding of why their band 12 intensities are strongly and inversely correlated to alterations of the exchange site environment. ${ }^{3,}$ $13 \quad 27,30-32$ The assignment of these Nafion bands as local symmetry based group modes is paradigm 14 shift from decades of history: The $1060 \mathrm{~cm}^{-1}$ and $969 \mathrm{~cm}^{-1}$ bands are COC-A, $-\mathrm{SO}_{3}{ }^{-1}$ and COC$15 \mathrm{~A},-\mathrm{SO}_{3}{ }^{-1}$ group modes respectively. Both modes are attributed to the same mechanically 16 coupled functional groups, which are listed in order of importance in their respective 17 assignments. The primary functional group contributors, in both modes, are the reverse of the 18 historical assignments. ${ }^{3,27,30,31,38,39}$

Proton and metal ion exchanged Nafion membranes are designated as Nafion-[H] and 20 Nafion-[M], respectively. ${ }^{27}$ At high states-of-hydration the Nafion-[M] sulfonate exchange site 21 environment is spectroscopically indistinguishable from that of Nafion-[H] because cation waters 22 of hydration preclude direct binding of the cations to the exchange site. 
The correlations of ionomer exchange site local symmetry, state-of-hydration, and ion-

2 exchange, to density functional theory (DFT) calculated normal modes and observed IR bands

3 would be better understood and reinforced if extended to other sulfonated ionomers. $3,30-32,38,40$

4 This work establishes symmetry-based IR group mode assignments for SPEEK-[H] and applies

5 them towards the analysis of dehydrated SPEEK-[M], where $\mathrm{M}$ is $\mathrm{Cu}^{2+}, \mathrm{Ni}^{2+}, \mathrm{Cd}^{2+}, \mathrm{Pb}^{2+}, \mathrm{Sr}^{2+}$ or $6 \mathrm{Ba}^{2+}$. 


\section{Experimental}

\section{Ion Exchange}

SPEEK Fumapem-E- 730 (Fumatech, Bietigheim-Bissingen, Germany) membranes were

4 used as is and soaked in $1 \mathrm{M}$ salt solutions $\left(\mathrm{CdCl}_{2}, \mathrm{CuSO}_{4}, \mathrm{NiCl}_{2}, \mathrm{~Pb}\left(\mathrm{NO}_{3}\right)_{2}, \mathrm{Ba}\left(\mathrm{C}_{2} \mathrm{H}_{3} \mathrm{O}_{2}\right)_{2}\right.$ and $\left.5 \quad \mathrm{Sr}\left(\mathrm{C}_{2} \mathrm{H}_{3} \mathrm{O}_{2}\right)_{2}\right)(48 \mathrm{hrs})$.

6 Membrane Transmission FTIR spectroscopy

SPEEK membranes were removed from solution, briefly rinsed with Nanopure ${ }^{\mathrm{TM}}$ water,

8 pat-dried with ChemWipes ${ }^{\mathrm{TM}}$, and placed in the Vertex 70 FT-IR spectrometer (Bruker, Billerica,

9 MA) to obtain the spectra of the fully hydrated membrane under ambient conditions. The sample

10 is then transferred into the Vertex 80 vacuum $(1.00 \mathrm{hPa})$ spectrometer (Bruker, Billerica, MA),

11 enclosed within a custom glovebox, for time dependent spectra. ${ }^{3}$ Spectra were obtained every

12 half hour for one full day, and then hourly until a steady state condition was attained (12-60

$13 \mathrm{hrs})$. Dehydration was continued on a high vacuum line $\left(60^{\circ} \mathrm{C}, 2\right.$ days $)$ equipped with a Welch

141402 DuoSeal vacuum pump, a glass oil diffusion pump (Ace Glass, Vineland, NJ) and a liquid $15 \mathrm{~N}_{2}$ trap. After dehydration, the sample bulb was transferred to the FT-IR glove box, and the 16 membrane returned to the Vertex 80 sample chamber for acquisition of a final spectrum. Spectra 17 were signal averaged (50 scans, $4 \mathrm{~cm}^{-1}$ resolution) using a DLaTGS detector. Data processing was completed using Bruker ${ }^{\mathrm{TM}}$ OPUS 6.5 $5^{\mathrm{TM}}$ software.

19 Attenuated Total Reflectance (ATR) Spectroscopy

A MIRacle ATR accessory (Pike Technologies Spectroscopic Creativity, Madison, WI)

21 with a ZnSe ATR crystal was used, inserted into the Vertex 70 FT-IR spectrometer sample stage.

22 A surface pressure of 815 psi was maintained over the $1.8 \mathrm{~mm}$ diameter ATR crystal. The 23 spectra were signal averaged from 100 scans at $4 \mathrm{~cm}^{-1}$ resolution with a dry-air purge at ambient 
1 temperature. Atmospheric compensation (to eliminate $\mathrm{H}_{2} \mathrm{O}$ and $\mathrm{CO}_{2}$ interference in the beam

2 path) was used in all measurements. Data processing for all infrared data was done with the

$3 \quad$ Bruker OPUS 6.5 software.

4 PEEK sulfuric acid treatment

A 20:1 vol/vol\% solution of hexanes (reagent grade, Sigma-Aldrich) and fuming sulfuric

6 acid was shaken vigorously in a separation funnel to diffuse $\mathrm{SO}_{3}$ into the hexanes. The organic

7 mixture (hexanes $\left./ \mathrm{SO}_{3}\right)$, was then extracted from the acid layer. PEEK $(2 \times 0.75 \mathrm{~cm}$, Novamem,

8 Zurich, Switzerland) was then submerged in the organic mixture for $6 \mathrm{~min}$. The treated

9 membrane was then dried using Kim wipes and attached to microscope slides using double-sided

10 adhesive tape. ATR spectra were taken directly from the slide-mounted treated PEEK.

11 Molecular Modeling Calculations

Unrestricted $\mathrm{DFT}^{41}$ with the $\mathrm{X} 3 \mathrm{LYP}^{42}$ functional was used for geometry optimizations and calculations of the normal mode frequencies of PEEK repeat units. The X3LYP is an

14 extension to the $\mathrm{B} 3 \mathrm{LYP}^{43}$ functional providing more accurate heats of formation. The 80 -atom 15 repeat unit consists of two PEEK monomer units plus an additional aromatic ring. Jaguar 8.7

16 (Schrodinger Inc., Portland, OR) was used with the all-electron 6-311G**++ Pople triple- $\zeta$ basis

17 set (“**” and "++" denote polarization ${ }^{41}$ and diffuse ${ }^{44}$ basis set functions, respectively). Output

18 files were converted to vibrational mode animations using the Maestro graphical user interface

19 (Schrodinger Inc., New York, NY). Calculations were carried out on the high performance

20 computing cluster at the University of Texas Rio Grande Valley with 72 nodes of Dual $2.67 \mathrm{Ghz}$

21 processors; each node with 48 GB RAM and 250 GB disk. DFT-calculated normal mode peaks

22 are denoted by superscript $(*)$ e.g. $983^{*} \mathrm{~cm}^{-1}$. Maestro animations for normal modes with

23 normalized intensity above $1 \%$ of the largest peak were selected for viewing. 
2 SPEEK-[H] vS. PEEK

Correlation of theoretically calculated normal modes to observed IR bands is a simpler

4 matter for SPEEK than Nafion. SPEEK is an ionomer for which the entire "backbone" structure,

5 less the sulfonate group, is available as poly(ether ether ketone) (PEEK) (Fig. 2, black structure).

6 No such backbone analog for Nafion is commercially available.

Hopefully, the lessons learned from Nafion will preclude the assignments of hydrated

8 SPEEK-[H] $1087 \mathrm{~cm}^{-1}\left(\mathrm{C}_{3 \mathrm{~V}, \mathrm{HF}}\right)$ and $1026 \mathrm{~cm}^{-1}\left(\mathrm{C}_{3 \mathrm{~V}, \mathrm{LF}}\right)$ bands as single functional group modes.

9 They are $\mathrm{C}_{3 \mathrm{~V}}$ group modes that involve mechanically coupled internal coordinates of both the dissociated sulfonate exchange site (with a local three fold axis of symmetry) and the nearest 11 neighbor ether link (Fig. 1, red circle).

Figure 2 shows the transmission spectra of both hydrated (solid red) and dehydrated 13 (dashed red) SPEEK-[H], superimposed upon the PEEK ATR spectrum (black). In general, the 14 correlation of measured band frequencies to theoretically calculated normal modes requires 15 additional experiments. 30, 32, 45 For example, experimental confirmation that the PEEK $1072^{\text {ATR }}$ $16 \mathrm{~cm}^{-1}$ band corresponds to Ring-A was obtained by surface treatment of PEEK with sulfuric acid 17 saturated hexane. The Ring-A structure was substantially altered to the point of complete 18 disappearance of the peak at $1072^{\mathrm{ATR}} \mathrm{cm}^{-1}$ (see Supplemental Figure S1).

The PEEK ATR spectrum shows backbone modes $(\mathrm{BB})$ at $1010^{\mathrm{ATR}} \mathrm{cm}^{-1}$ and $1072^{\mathrm{ATR}}$ $20 \mathrm{~cm}^{-1}$ (black dashed vertical line highlights) which are substantially altered by sulfonation of 21 Ring-A (dashed red spectrum). The $1010^{\mathrm{ATR}} \mathrm{cm}^{-1}$ backbone band shifts to the SPEEK-[H] band 22 at $1016 \mathrm{~cm}^{-1}$. The $1016 \mathrm{~cm}^{-1}$ band, upon hydration of SPEEK-[H], is enveloped by the $\mathrm{C}_{3 \mathrm{~V}, \mathrm{LF}}$ 23 mode (solid red spectrum) and thus persists as a shoulder. The dehydrated SPEEK-[H] $\mathrm{C}_{1}$ mode 
1 at $1070 \mathrm{~cm}^{-1}$ is unrelated to the PEEK backbone mode at $1072^{\mathrm{ATR}} \mathrm{cm}^{-1}$. In fact, the $\mathrm{C}_{1}$ mode

2 vanishes upon full hydration (blue arrow to solid red spectrum) while the $\mathrm{C}_{3 \mathrm{~V}, \mathrm{HF}}$ and $\mathrm{C}_{3 \mathrm{~V}, \mathrm{LF}}$

3 appear at $1087 \mathrm{~cm}^{-1}$ and $1026 \mathrm{~cm}^{-1}$ (solid red vertical line highlights). IR spectra (from $1600 \mathrm{~cm}^{-1}$

4 to $800 \mathrm{~cm}^{-1}$ ) of PEEK, dehydrated SPEEK-[H], and hydrated SPEEK-[H] with overlaid DFT-

5 calculated normal modes are available in Supplemental Figure S2. Group mode PEEK and

6 SPEEK-[H] band assignments were obtained by eigenvector visualization. (Table 1). ${ }^{3,30,31}$

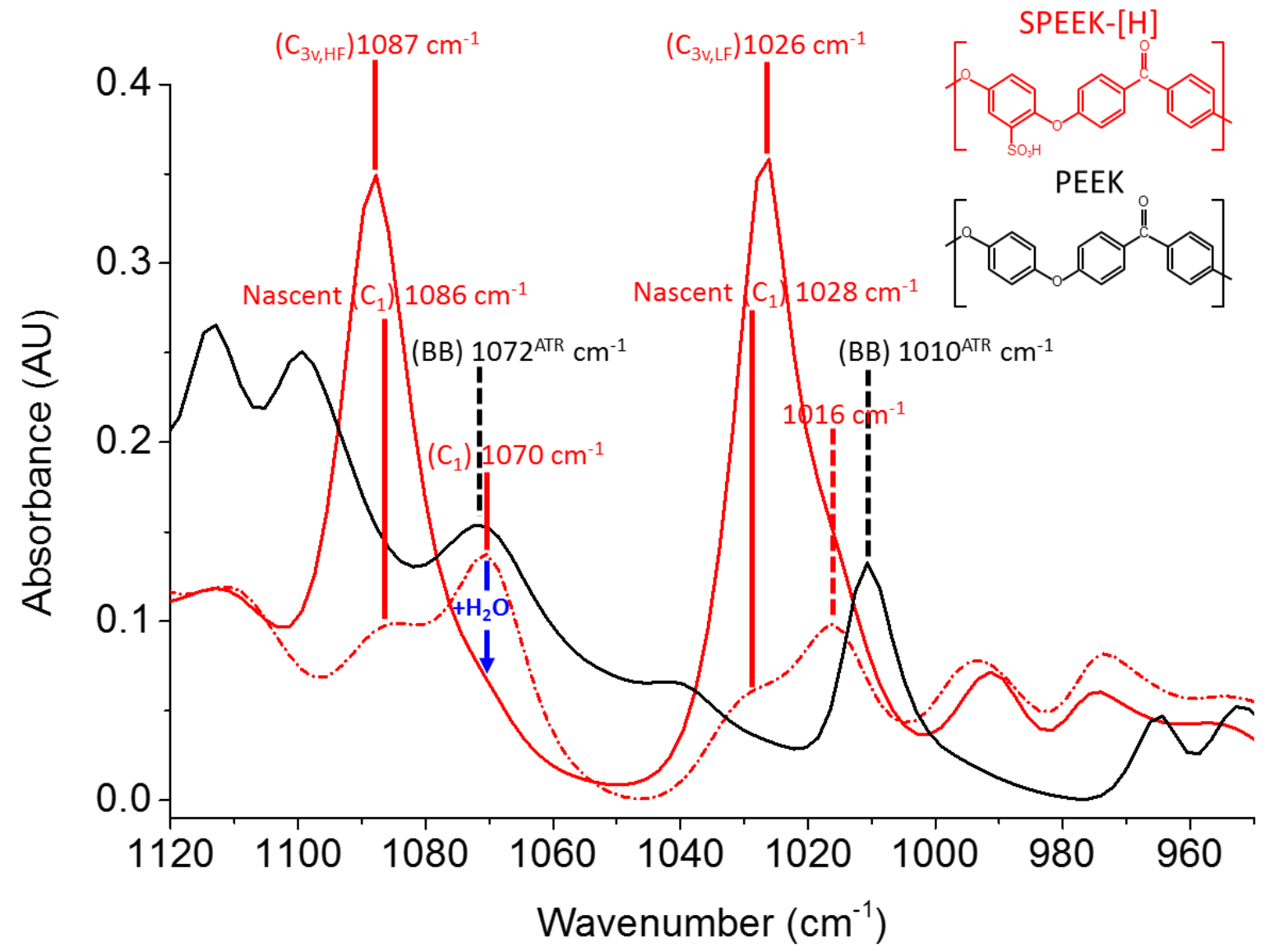

7 Figure 2. SPEEK-[H] transmission spectra (red): hydrated (solid), dehydrated (dashed). PEEK

8 ATR spectrum (black). Dashed vertical lines highlight bands insensitive to the exchange site 9 environment. 
$2{ }^{1}$ ). These experimental bands are tentatively assigned as nascent $C_{1}$ bands (Fig. 2, dashed red 3 spectrum). Visualization of eigenvector animations show substantial contribution by the $-\mathrm{SO}_{3} \mathrm{H}$ 4 form of the exchange site. The two bands are not yet experimentally confirmed as $\mathrm{C}_{1}$ bands, 5 because $\mathrm{C}_{3 \mathrm{~V}, \mathrm{HF}}$ and $\mathrm{C}_{3 \mathrm{~V}, \mathrm{LF}}$ overlap at those wavenumbers and preclude definitive assignments. It 6 is hoped that further work, quantitatively decomposing DFT-calculated normal modes into pure 7 modes (i.e., individual vibrational motions of specific functional groups), ${ }^{46}$ will allow 8 confirmation of the bands as $\mathrm{C}_{1}$ group modes. 


\begin{tabular}{|c|c|c|c|c|c|}
\hline & $\begin{array}{r}\text { Transmission } \\
\left(\mathrm{cm}^{-1}\right)\end{array}$ & $\begin{array}{r}\text { ATR } \\
\left(\mathrm{cm}^{-1}\right)\end{array}$ & $\begin{array}{r}\text { DFT } \\
\left(\mathrm{cm}^{-1}\right)\end{array}$ & Normal mode components & $\begin{array}{l}\text { Band } \\
\text { Assignment }\end{array}$ \\
\hline Hydrated Nafion-[H] & $\begin{array}{r}969 \\
1061\end{array}$ & $\begin{array}{r}971^{\mathrm{ATR}} \\
1056^{\mathrm{ATR}}\end{array}$ & $\begin{array}{r}983^{*} \\
1059^{*}\end{array}$ & $\begin{array}{l}\mathrm{SO}_{3}^{-} v_{\mathrm{s}}, \mathrm{COC}-\mathrm{A} v_{\mathrm{as}} \\
\mathrm{COC}-\mathrm{A} v_{\mathrm{as}}, v_{\mathrm{s}} \mathrm{SO}_{3}^{-}\end{array}$ & $\begin{array}{l}\mathrm{C}_{3 \mathrm{v}, \mathrm{LF}} \\
\mathrm{C}_{3 \mathrm{v}, \mathrm{HF}}\end{array}$ \\
\hline Dehydrated Nafion-[H] & $\begin{array}{r}910 \\
1414\end{array}$ & & $\begin{array}{r}786^{*} \\
1405^{*}\end{array}$ & $\begin{array}{l}\mathrm{SO}_{3} \mathrm{H} v_{\mathrm{s}}, \mathrm{COC}-\mathrm{A} v_{\mathrm{s}} \\
\mathrm{SO}_{3} \mathrm{H} v_{\mathrm{as}}, \mathrm{COC}-\mathrm{A} v_{\mathrm{as}}\end{array}$ & $\begin{array}{l}\mathrm{C}_{1, \mathrm{LF}} \\
\mathrm{C}_{1, \mathrm{HF}}\end{array}$ \\
\hline Hydrated SPEEK-[H] & $\begin{array}{l}1016 \\
1026 \\
1087\end{array}$ & $\begin{array}{l}1020^{\mathrm{ATR}} \\
1076^{\mathrm{ATR}}\end{array}$ & $\begin{array}{r}943 * \\
981 * \\
1029 * \\
1068 *\end{array}$ & $\begin{array}{l}\Phi_{\mathrm{b}, \mathrm{OOP}}, \mathrm{C}=\mathrm{O} \delta_{\mathrm{s}} \mathrm{v}_{\mathrm{s}}, \mathrm{CH}_{\mathrm{b}} v_{\mathrm{as}} \\
\Phi_{\mathrm{a}, \mathrm{IP}}, \mathrm{SO}_{3}^{-} v_{\mathrm{s}} \\
\Phi_{\mathrm{a}, \mathrm{IP}}, \mathrm{CH}_{\mathrm{a}} v_{\mathrm{as}} \\
\Phi_{\mathrm{a}, \mathrm{IP}}, \mathrm{CH}_{\mathrm{a}} v_{\mathrm{as}}, \mathrm{SO}_{3}^{-} v_{\mathrm{s}}\end{array}$ & $\begin{array}{l}\mathrm{C}_{3 \mathrm{v}, \mathrm{LF}} \\
\mathrm{C}_{3 \mathrm{v}, \mathrm{HF}}\end{array}$ \\
\hline Dehydrated SPEEK-[H] & $\begin{array}{r}898 \\
1016 \\
1028 \\
1070 \\
1086 \\
1362\end{array}$ & & $\begin{array}{r}769 * \\
959^{*} \\
1069^{*} \\
1071^{*} \\
1108^{*} \\
1374^{*}\end{array}$ & $\begin{array}{l}\Phi_{\mathrm{a}, \mathrm{OOP}}, \Phi_{\mathrm{b}, \mathrm{OOP}}, \mathrm{SO}_{3} \mathrm{H} v_{\mathrm{s}} \\
\mathrm{C}=\mathrm{O} \delta_{\mathrm{s}} \mathrm{v}_{\mathrm{s}}, \Phi_{\mathrm{b}, \mathrm{OOP}}, \mathrm{CH}_{\mathrm{b}} v_{\mathrm{as}} \\
\Phi_{\mathrm{a}, \mathrm{IP}}, \mathrm{SO}_{3} \mathrm{H} v_{\mathrm{as}}, \mathrm{CH}_{\mathrm{a}} v_{\mathrm{as}} \\
\mathrm{SO}_{3} \mathrm{H} v_{\mathrm{as}}, \Phi_{\mathrm{b}, \mathrm{IP}}, \Phi_{\mathrm{a}, \mathrm{IP}} \\
\Phi_{\mathrm{a}, \mathrm{IP}}, \mathrm{SO}_{3} \mathrm{H} v_{\mathrm{as}} \\
\Phi_{\mathrm{a}, \mathrm{IP}}, \Phi_{\mathrm{b}, \mathrm{IP}}, \mathrm{SO}_{3} \mathrm{H} v_{\mathrm{as}}\end{array}$ & $\begin{array}{l}\mathrm{C}_{1, \mathrm{LF}} \\
\text { Nascent } \mathrm{C}_{1} \\
\mathrm{C}_{1} \\
{\text { Nascent } \mathrm{C}_{1}} \\
\mathrm{C}_{1, \mathrm{HF}}\end{array}$ \\
\hline PEEK & & $\begin{array}{l}1010^{\text {ATR }} \\
1072^{\text {ATR }}\end{array}$ & $\begin{array}{r}944 * \\
1032 *\end{array}$ & $\begin{array}{l}\Phi_{\mathrm{b}, \mathrm{OOP}}, \mathrm{C}=\mathrm{O} \delta_{\mathrm{s}} \mathrm{v}_{\mathrm{s}}, \mathrm{CH}_{\mathrm{b}} \mathrm{v}_{\mathrm{as}} \\
\Phi_{\mathrm{a}, \mathrm{IP}}, \mathrm{CH}_{\mathrm{a}} v_{\mathrm{as}}\end{array}$ & $\begin{array}{l}\mathrm{BB} \\
\mathrm{BB}\end{array}$ \\
\hline
\end{tabular}

1 Table 1 - Transmission, ATR, and DFT-calculated normal modes for Nafion-[H] (hydrated and 2 dehydrated), SPEEK-[H] (hydrated and dehydrated), and PEEK. Subscripts a and b refer to Ring 3 a and Ring b. $v_{\mathrm{as}}$ : asymmetric stretching. $v_{\mathrm{s}}$ : symmetric stretching. $\delta_{\mathrm{s}}$ : bending, $\delta_{\mathrm{u}}$ : umbrella 4 bending. $\Phi$ : ring deformation. OOP: out of plane. IP: in plane. BB: backbone. 
Figure 3(a) shows transmission spectra of hydrated SPEEK-[H] (red) and dehydrated

3 SPEEK- $[\mathrm{H}]$ (blue). The transition of the exchange site local symmetry from $\mathrm{C}_{3 \mathrm{~V}}$ to $\mathrm{C}_{1}$ is

4 evidenced by the complete loss of the $\mathrm{C}_{3 \mathrm{~V}}$ bands (red line highlights) concomitant with the

5 emergence of the $C_{1, \mathrm{LF}}$ at $898 \mathrm{~cm}^{-1}$ and the $\mathrm{C}_{1, \mathrm{HF}}$ at $1362 \mathrm{~cm}^{-1}$ (blues line highlights). Figure 3(b)

6 shows superimposed fully hydrated (red) SPEEK-[Cd] and dehydrated (blue) spectra. In SPEEK-

$7[\mathrm{Cd}]$ spectra, a $\mathrm{C}_{3 \mathrm{~V}, \mathrm{LF}}$ band persists at all states-of-hydration. At high states of hydration, the

8 exchange site is essentially a hydrated SPEEK- $[\mathrm{H}]$ environment because the cations are screened

9 from the exchange site. As the membrane is dehydrated, the sulfonate $\mathrm{C}_{3 \mathrm{~V}, \mathrm{LF}}$ at $1026 \mathrm{~cm}^{-1}$

10 transitions to a $\mathrm{Cd}^{2+}$ complexed sulfonate $\mathrm{C}_{3 \mathrm{~V}, \mathrm{LF}}$ at $1016 \mathrm{~cm}^{-1}$. The $\mathrm{Cd}^{2+}$ resides in the sulfur

11 trioxide pocket, ${ }^{27}$ with substantial orbital overlap with the sulfur atom. The small $\mathrm{C}_{1, \mathrm{HF}}$ shoulder

12 at $1362 \mathrm{~cm}^{-1}$ suggests trace amounts of sulfonic acid $\left(\mathrm{C}_{1}\right)$ groups. A SPEEK-[Cd] $\mathrm{C}_{1, \mathrm{LF}}$, 13 analogous to the SPEEK-[H] $\mathrm{C}_{1, \mathrm{LF}}$ at $898 \mathrm{~cm}^{-1}$, is never observed.

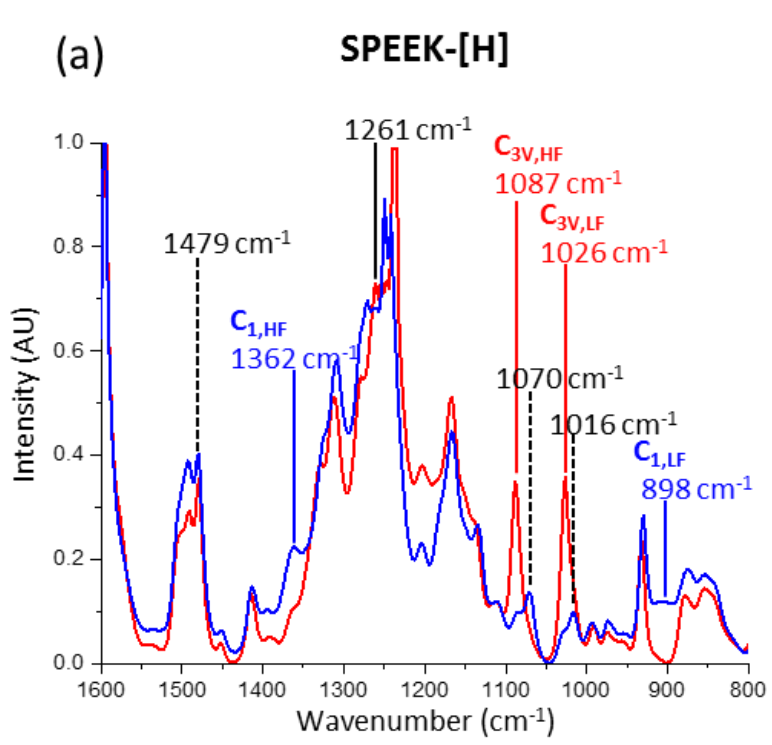

(b)

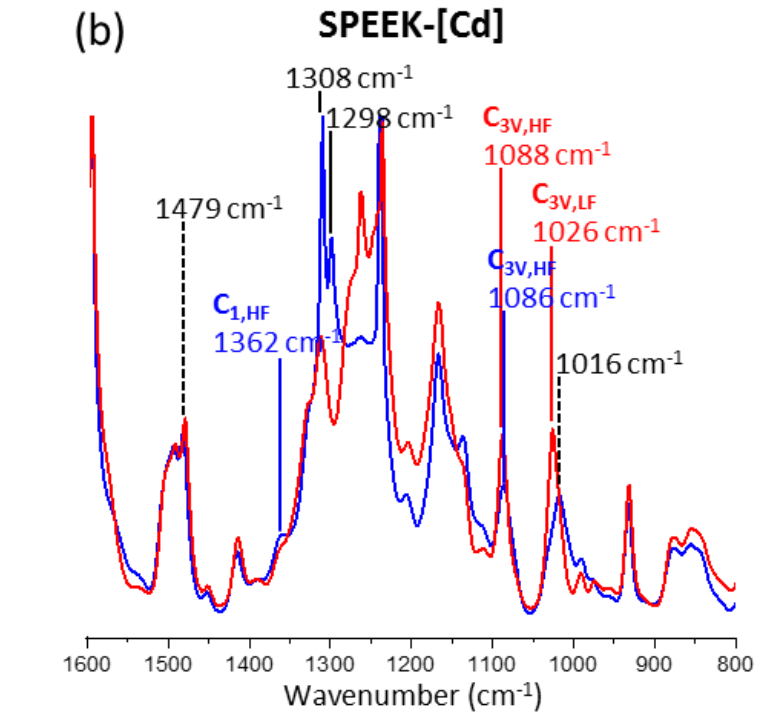

14 Figure 3. SPEEK transmission spectra: hydrated (red), dehydrated (blue). (a) SPEEK-[H]. (b)

\section{SPEEK-[Cd].}


$2 \mathrm{Ba}^{2+}$ ) are shown in Figure 4(a) and 4(b), in order of cation hydration enthalpy. For greater detail,

3 transmission spectra of superimposed hydrated/dehydrated SPEEK-[M] are in Supplemental

4 Figures S4-S8. The spectra of fully hydrated SPEEK-[M] all show "hydrated" SPEEK-[H] $\mathrm{C}_{3 \mathrm{~V}}$

5 features irrespective of the cation, because cation hydration spheres preclude direct binding to

6 the exchange site (Fig. 4a).

$7 \quad$ During SPEEK-[M] dehydration, cation hydration spheres are stripped away enabling

8 direct binding of cations to the exchange site: SPEEK-[M] $\mathrm{C}_{3 \mathrm{~V}}$ bands emerge at the expense of 9 the SPEEK-[H] $\mathrm{C}_{3 \mathrm{~V}}$ bands (Fig. 4a to $4 \mathrm{~b}$ ). A rescaled inset (Fig. 4e) shows that the $\mathrm{C}_{1, \mathrm{LF}}$ band 10 appears in SPEEK-[H] but is not observed in any of the SPEEK-[M] spectra. However, $\mathrm{C}_{1}$ 11 symmetry is not completely absent from SPEEK-[M] spectra. The dehydrated SPEEK-[M] $\mathrm{C}_{1, \mathrm{HF}}$ 12 (Fig. 4c) intensity grows with increasing hydration enthalpy. Figure 4(d) highlights this 13 remarkable trend: Hydration spheres of ions with large hydration enthalpies are so difficult to 14 strip, that maximally dehydrated membranes continue to exhibit some SPEEK-[H] $\mathrm{C}_{1, \mathrm{HF}}$ band 15 intensity.

16

17

18

19

20

21 
(a)

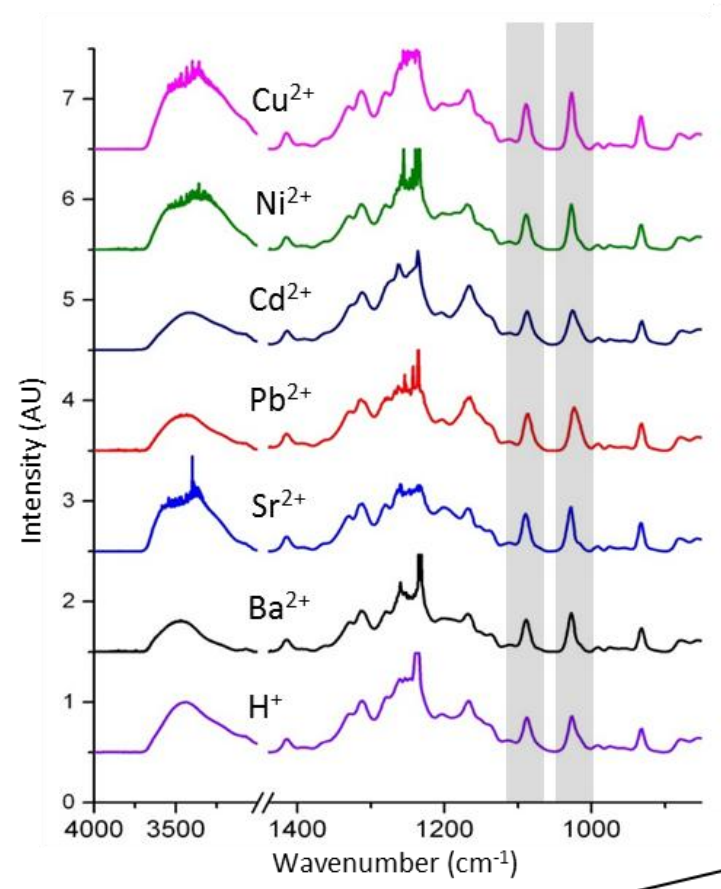

(c)

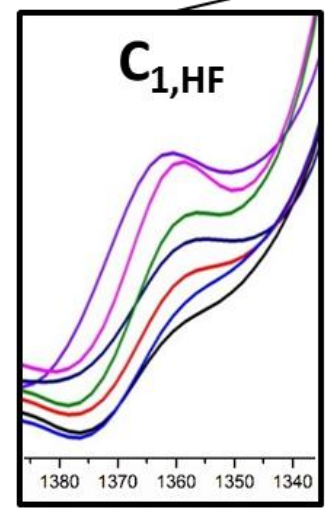

(d) (b) Dehydrated SPEEK-[M]
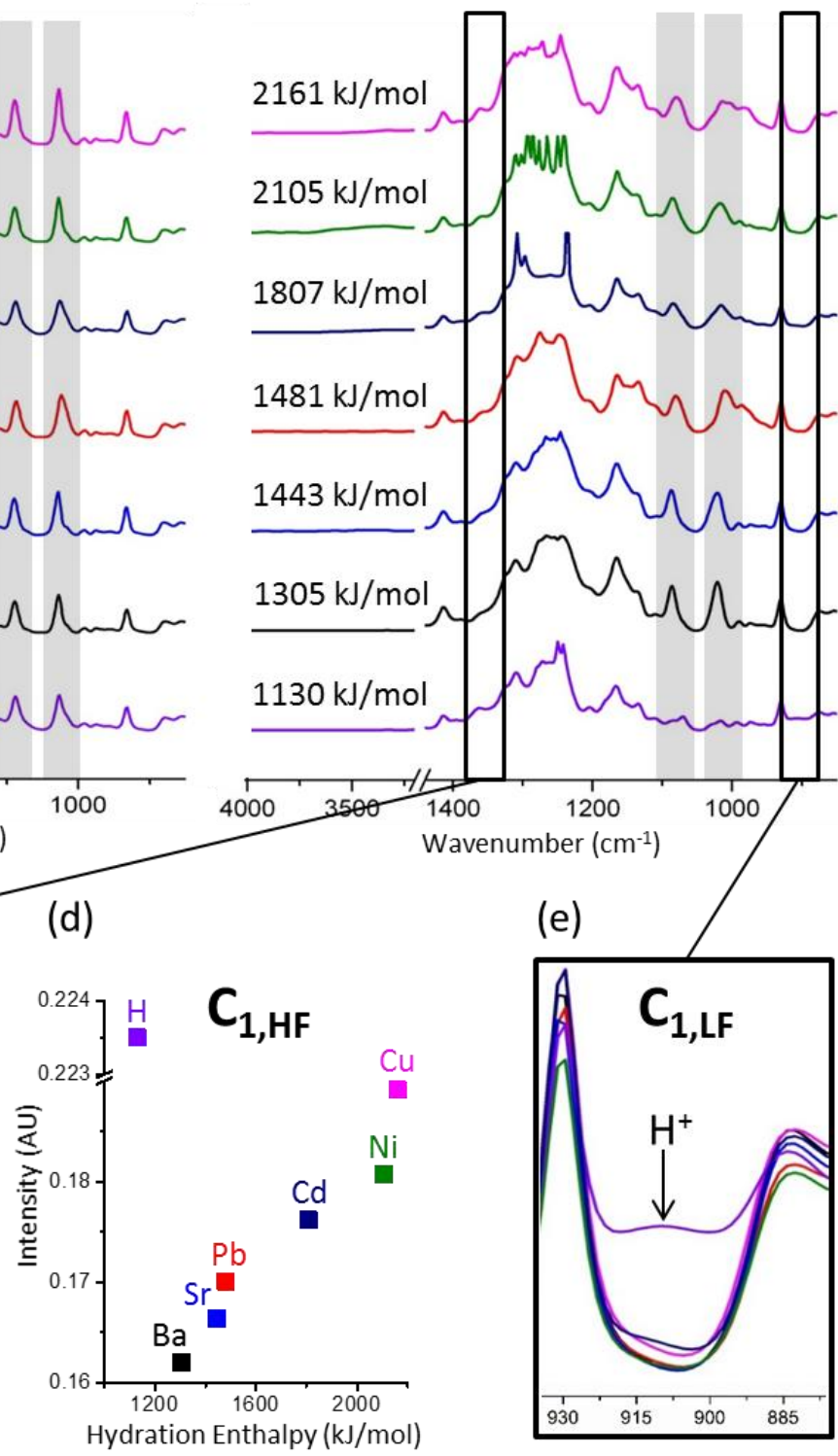

(e)

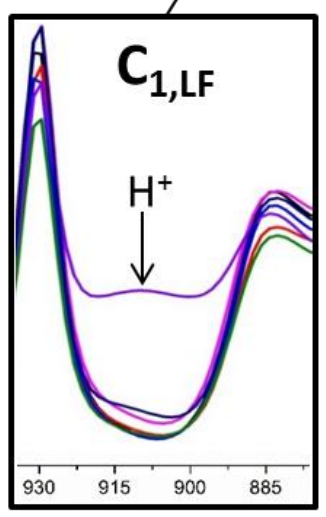

1 Figure 4. SPEEK-[M] transmission spectra: (a) hydrated, (b) dehydrated. (c) Highlighted $\mathrm{C}_{1, \mathrm{HF}}$

2 band. (d) $\mathrm{C}_{1, \mathrm{HF}}$ band intensity versus metal ion hydration enthalpy. (g) Highlighted $\mathrm{C}_{1, \mathrm{LF}}$ band. 
The tabulated SPEEK-[M] $\mathrm{C}_{3 \mathrm{~V}}$ bands (Table 2) confirm the overwhelming presence of a

2 local $\mathrm{C}_{3 \mathrm{~V}}$ symmetry at the dehydrated SPEEK-[M] exchange site. This can be considered with

3 respect to charge balance. An exchange site - divalent ion pair yields a net positive charge that

4 can be formally charge balanced by (1) another cross-linking exchange site or (2) a hydroxide 5 ion.

6 Hydroxide balancing yields a proton (from $\mathrm{H}_{2} \mathrm{O}$ ) that, during dehydration, will bind to an

7 exchange site with $\mathrm{C}_{1}$ symmetry. The presence of the low intensity SPEEK-[M] $\mathrm{C}_{1, \mathrm{HF}}$ band

8 suggests low levels of hydroxide ion balancing. Figure 5 is a model of SPEEK that shows both a

9 metal ion cross-link and sulfonic acid groups.

\begin{tabular}{lcccccc}
\hline & $-\Delta \mathrm{H}_{\mathrm{Hyd}}$ & \multicolumn{2}{c}{ Hydrated $\left(\mathrm{cm}^{-1}\right)$} & \multicolumn{2}{c}{ Dehydrated $\left(\mathrm{cm}^{-1}\right)$} & \\
\cline { 2 - 5 } Ions & $(\mathrm{kJ} / \mathrm{mol})$ & $\mathrm{C}_{3 \mathrm{~V}, \mathrm{HF}}$ & $\mathrm{C}_{3 \mathrm{~V}, \mathrm{LF}}$ & $\mathrm{C}_{3 \mathrm{~V}, \mathrm{HF}}$ & $\mathrm{C}_{3 \mathrm{~V}, \mathrm{LF}}$ & Figure \\
\hline $\mathrm{Cu}^{2+}$ & 2161 & 1088 & 1026 & 1080 & - & $\mathrm{S} 3$ \\
$\mathrm{Ni}^{2+}$ & 2105 & 1089 & 1028 & 1084 & - & $\mathrm{S} 4$ \\
$\mathrm{Cd}^{2+}$ & 1807 & 1088 & 1026 & 1086 & - & $3 \mathrm{~b}$ \\
$\mathrm{~Pb}^{2+}$ & 1481 & 1087 & 1024 & 1080 & - & $\mathrm{S} 5$ \\
$\mathrm{Sr}^{2+}$ & 1443 & 1089 & 1028 & 1088 & 1020 & $\mathrm{~S} 6$ \\
$\mathrm{Ba}^{2+}$ & 1305 & 1088 & 1027 & 1086 & 1022 & $\mathrm{~S} 7$ \\
$\mathrm{H}^{+}$ & 1130 & 1087 & 1026 & - & - & $3 \mathrm{a}$ \\
\hline
\end{tabular}

Table 2 -Ion-exchanged SPEEK $\mathrm{C}_{3 \mathrm{~V}}$ transmission bands listed with ion hydration enthalpy.

11 Figures S3-S8 are in Supplementary Data. 


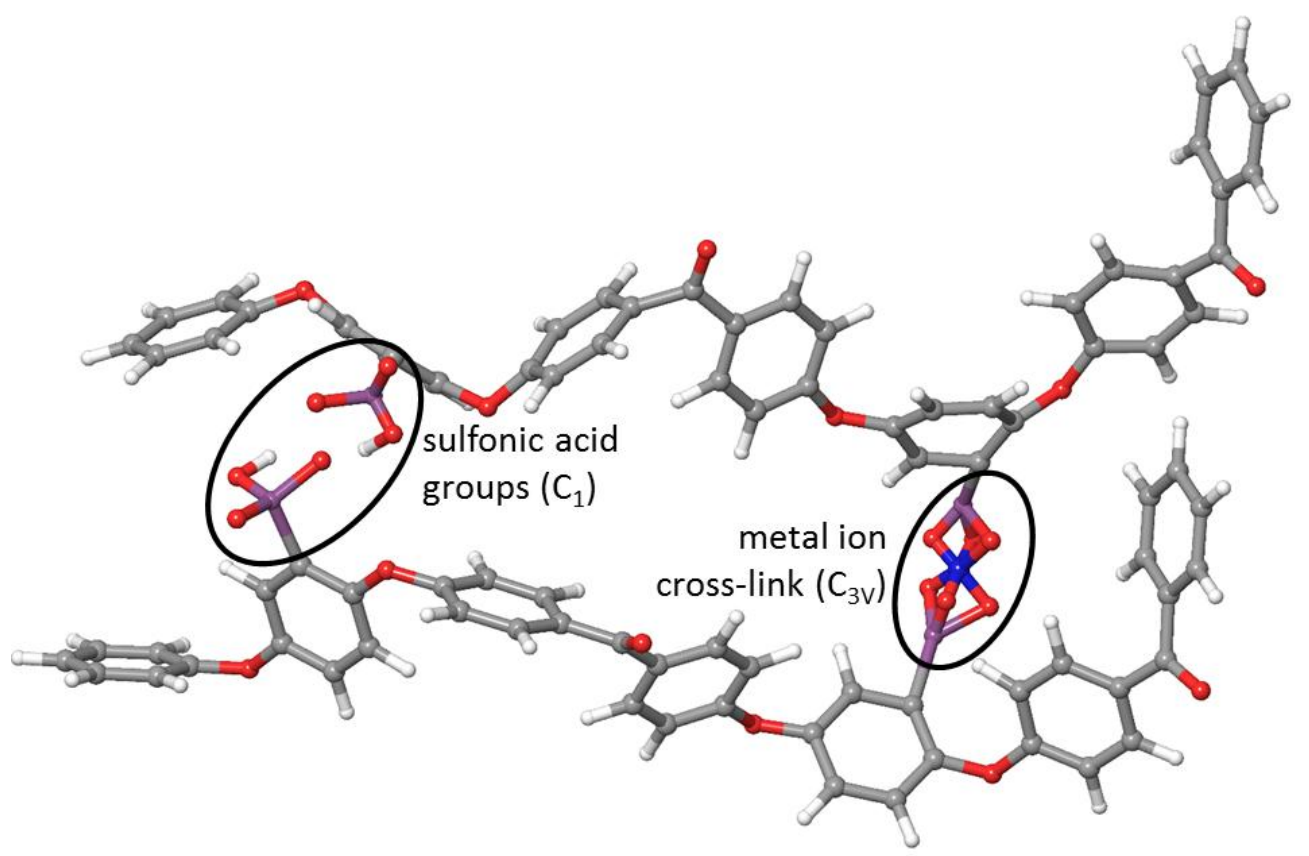

1 Figure 5: Model of SPEEK-[M] with sulfonic acid groups and a metal ion cross-link. Carbon 2 (gray), Oxygen (red), Sulfur (purple), Metal ion (blue).

The degree of cross-linking is expected to be inversely correlated to the SPEEK-[M]

$4 \quad \mathrm{C}_{1, \mathrm{HF}}$ band intensity. The $\mathrm{C}_{1, \mathrm{HF}}$ band intensity versus cation hydration enthalpy is shown in Fig.

5 4d. Ions with low hydration enthalpy, such as $\mathrm{Ba}^{2+}, \mathrm{Sr}^{2+}$, and $\mathrm{Pb}^{2+}$, have smaller $\mathrm{C}_{1, \mathrm{HF}}$ bands (i.e., strong metal ion - exchange site interactions and less likelihood of the sulfonic acid form of the

7 exchange site), resulting from a large degree of cross-linking. Cations with higher hydration

8 enthalpies $\left(\mathrm{Cd}^{2+}, \mathrm{Ni}^{2+}\right.$ and $\left.\mathrm{Cu}^{2+}\right)$ bind weakly to the exchange site. The exchange site cannot

9 compete with waters of hydration, resulting in fewer cross-links. ${ }^{22}$ Gasa et al. showed that $\mathrm{Ba}^{2+}$

10 cation cross-linking renders a sulfonated ionomer less capable of water swelling as a function of

11 methanol-water activity. ${ }^{22}$ Luu et al. continued by stating the reduction in water uptake was

12 associated with the reduced ion cluster size revealed by small angle X-ray scattering analysis of

$13 \mathrm{Sr}^{2+}$ ion-exchanged SPEEK. ${ }^{8}$ The reported enhanced cross-linking capabilities of $\mathrm{Ba}^{2+}$ and $\mathrm{Sr}^{2+}$

14 correlate with their positions in Fig. 4d. ${ }^{8,22}$ The lower hydration enthalpy of $\mathrm{Ba}^{2+}$ and $\mathrm{Sr}^{2+}$ enable

15 SPEEK-[M] exchange sites to successfully compete with hydration waters and thus yield brittle, 
1 cross-linked ${ }^{20}$ membranes.

The categorizations of IR group modes in terms of the local symmetry of the ion

3 complexing site can be extended beyond organic structures. There are reports of $\mathrm{C}_{3 \mathrm{~V}}$ quasilattice

4 site symmetries in molten metal sulfates having two sulfates specifically associated with each

5 divalent metal ion. ${ }^{47}$

\section{Conclusion}

The dissociated sulfonate exchange site of fully hydrated SPEEK- $[\mathrm{H}]$ has a local $\mathrm{C}_{3 \mathrm{~V}}$

8 symmetry. The vibrational normal mode internal coordinates of the sulfonate group are

9 mechanically coupled to the nearest neighbor ether link giving rise to a $C_{3 \mathrm{~V}, L F}$ band at $1026 \mathrm{~cm}^{-1}$

10 and the higher frequency $\mathrm{C}_{3 \mathrm{~V}, \mathrm{HF}}$ at $1087 \mathrm{~cm}^{-1}$. Infrared spectra of fully hydrated SPEEK-[H] and

11 SPEEK-[M], where $\mathrm{M}$ are divalent cations, are spectroscopically indistinguishable, because

12 cation waters of hydration shield the cation from the sulfonate exchange site inner sphere (i.e.,

13 hydrated SPEEK-[M] exhibits the SPEEK- $[\mathrm{H}] \mathrm{C}_{3 \mathrm{~V}}$ modes). When SPEEK- $[\mathrm{H}]$ is dehydrated, the

14 exchange site associates to the sulfonic acid form $\left(-\mathrm{SO}_{3} \mathrm{H}\right)$, which has no local symmetry $\left(\mathrm{C}_{1}\right)$.

15 When SPEEK-[M] undergoes dehydration, the ion hydration spheres are stripped away, and the

16 SPEEK-[M] $\mathrm{C}_{3 \mathrm{~V}}$ bands supplant SPEEK-[H] $\mathrm{C}_{3 \mathrm{~V}}$ bands. Divalent cations bind to exchange sites

17 and induce cross-linking with $\mathrm{C}_{3 \mathrm{~V}}$ local symmetry at the exchange sites. For all metals of this

18 study, a minority of exchange sites within SPEEK-[M] remain protonated when the membrane is

19 dehydrated. This yields low intensity SPEEK-[M] $\mathrm{C}_{1, \mathrm{HF}}$ bands at $\sim 1360 \mathrm{~cm}^{-1}$ with intensities (1)

20 directly correlated to the cation hydration enthalpy and (2) negatively correlated to the extent of

21 membrane cross-linking. As expected, the SPEEK-[M] $\mathrm{C}_{1, \mathrm{HF}}$ band range is centered around the

22 SPEEK-[H] $\mathrm{C}_{1, \mathrm{HF}}$ band at $1362 \mathrm{~cm}^{-1}$. 
1. X. F. Li, Z. Wang, H. Lu, C. J. Zhao, H. Na and C. Zhao, Journal of Membrane Science, 2005, 254, 147-155.

2. V. R. Hande, S. K. Rath, S. Rao and M. Patri, Journal of Membrane Science, 2011, 372, 40-48.

3. J. Doan, E. Kingston, I. Kendrick, K. Anderson, N. Dimakis, P. Knauth, M. L. Di Vona and E. S. Smotkin, Polymer, 2014, 55, 4671-4676.

4. E. Negro, M. Vittadello, K. Vezzu, S. J. Paddison and V. Noto, Solid State lonics, 2013, 252, 84-92.

5. G. Hougham, Fluoropolymers 1, Springer, 1999.

6. L. Liberti and F. G. Helfferich, Mass transfer and kinetics of ion exchange, Springer, 1983.

7. A. Basile, L. Paturzo, A. Iulianelli, I. Gatto and E. Passalacqua, Journal of Membrane Science, 2006, 281, 377-385.

8. D. X. Luu and D. Kim, Solid State Ion., 2011, 192, 627-631.

9. S. H. de Almeida and Y. Kawano, Journal of Thermal Analysis and Calorimetry, 1999, 58, 569-577.

10. C. Bas, L. Flandin, A. S. Danero, E. Claude, E. Rossinot and N. D. Alberola, Journal of Applied Polymer Science, 2010, 117, 2121-2132.

11. J. M. Song, J. Shin, J. Y. Sohn and Y. C. Nho, Macromolecular Research, 2011, 19, 1082-1089.

12. R. Narducci, M. L. Di Vona and P. Knauth, Journal of Membrane Science, 2014, 465, 185-192.

13. S. G. Feng, Y. M. Shang, G. S. Liu, W. Q. Dong, X. F. Xie, J. M. Xu and V. K. Mathur, Journal of Power Sources, 2010, 195, 6450-6458.

14. T. Yang and C. Liu, International Journal of Hydrogen Energy, 2011, 36, 5666-5674.

15. X. Wu, X. Wang, G. He and J. Benziger, Journal of Polymer Science Part B-Polymer Physics, 2011, 49, 1437-1445.

16. Y. Paik, S. A. Chae, O. H. Han, S. Y. Hwang and H. Y. Ha, Polymer, 2009, 50, 2664-2673.

17. S. Xue and G. Yin, Polymer, 2006, 47, 5044-5049.

18. N. Zhang, G. Zhang, D. Xu, C. Zhao, W. Ma, H. Li, Y. Zhang, S. Xu, H. Jiang, H. Sun and H. Na, International Journal of Hydrogen Energy, 2011, 36, 11025-11033.

19. Y.-S. Ye, Y.-C. Yen, C.-C. Cheng, W. Y. Chen, L.-T. Tsai and F.-C. Chang, Polymer, 2009, 50, 31963203.

20. H. Y. Hou, B. Maranesi, J. F. Chailan, M. Khadhraoui, R. Polini, M. L. Di Vona and P. Knauth, Journal of Materials Research, 2012, 27, 1950-1957.

21. M. L. Di Vona, L. Pasquini, R. Narducci, K. Pelzer, A. Donnadio, M. Casciola and P. Knauth, Journal of Power Sources, 2013, 243, 488-493.

22. J. V. Gasa, R. A. Weiss and M. T. Shaw, Journal of Membrane Science, 2007, 304, 173-180.

23. S. Zhong, X. Cui, H. Cai, T. Fu, C. Zhao and H. Na, Journal of Power Sources, 2007, 164, 65-72.

24. M. L. Di Vona, G. Alberti, E. Sgreccia, M. Casciola and P. Knauth, International Journal of Hydrogen Energy, 2012, 37, 8672-8680.

25. R. Narducci, M. Di Vona and P. Knauth, J. Membr. Sci., 2014, 465, 185-192.

26. S. Quezado, J. C. T. Kwak and M. Falk, Canadian Journal of Chemistry, 1984, 62, 958-966.

27. J. Doan, N. E. Navarro, D. Kumari, K. Anderson, E. Kingston, C. Johnson, A. Vong, N. Dimakis and E. S. Smotkin, Polymer, 2015, 73, 34-41.

28. H. Y. Liang, X. P. Qiu, S. C. Zhang, W. T. Zhu and L. Q. Chen, Journal of Applied Electrochemistry, 2004, 34, 1211-1214.

29. R. R. Garsuch, D. B. Le, A. Garsuch, J. Li, S. Wang, A. Farooq and J. R. Dahn, J. Electrochem. Soc., 2008, 155, A721-A724.

30. M. Webber, N. Dimakis, D. Kumari, M. Fuccillo and E. S. Smotkin, Macromolecules, 2010, 43, 5500-5502.

31. I. Kendrick, D. Kumari, A. Yakaboski, N. Dimakis and E. S. Smotkin, J. Am. Chem. Soc., 2010, 132, 17611-17616. 
32. I. Kendrick, A. Yakaboski, E. Kingston, J. Doan, N. Dimakis and E. S. Smotkin, J. Polym. Sci. Pt. BPolym. Phys., 2013, 51, 1329-1334.

33. I. Kendrick, J. Doan and E. S. Smotkin, in Vibrational Spectroscopy at Electrified Interfaces, eds. A. Wieckowski, C. Korzeniewski and B. Braunschweig, 2013, pp. 327-344.

34. E. Gonzalez, J. Arbiol and V. F. Puntes, Science, 2011, 334, 1377-1380.

35. D. S. Warren and A. J. McQuillan, J. Phys. Chem. B, 2008, 112, 10535-10543.

36. K. M. Cable, K. A. Mauritz and R. B. Moore, Journal of Polymer Science, Part B: Polymer Physics, 1995, 33, 1065-1072.

37. Y. Q. Wang, Y. Kawano, S. R. Aubuchon and R. A. Palmer, Macromolecules, 2003, 36, 1138-1146.

38. I. Kendrick, J. Fore, J. Doan, A. Vong, N. Loupe, M. Diem and E. S. Smotkin, Journal of The Electrochemical Society. In Press, 2016, 163.

39. N. Loupe, J. Doan and E. S. Smotkin, Manuscript Submitted, 2016.

40. N. Loupe, J. Doan and E. Smotkin, Submitted to Catalysis Today on December 13, 2015.

41. P. Hohenberg and W. Kohn, Physical Review, 1964, 136, B864-B871.

42. X. Xu, Q. S. Zhang, R. P. Muller and W. A. Goddard, Journal of Chemical Physics, 2005, 122, 14.

43. A. D. Becke, Journal of Chemical Physics, 1993, 98, 5648-5652.

44. W. Kohn and L. J. Sham, Physical Review, 1965, 140, A1133-A1138.

45. D. I. Bower and W. F. Maddams, The Vibrational Spectroscopy of Polymers, Cambridge University Press, Cambridge, 1989.

46. J. Doan, T. Mion, I. Kendrick, A. Yakaboski, D. Kumari, A. Vong, N. Dimakis and E. S. Smotkin, Manuscript in preparation, 2015.

21

22

47. R. Hester and K. Krishnan, The Journal of Chemical Physics, 1968, 49, 4356-4360. 